Research Article

\title{
Effects of Additive $\beta$-Cyclodextrin on the Performances of Green Tea Infusion
}

\author{
Qianying Dai, Sitong Liu, Huozhu Jin, Yurong Jiang, and Tao Xia \\ State Key Laboratory of Tea Plant Biology and Utilization, Anhui Agricultural University, Hefei, Anhui 230036, China \\ Correspondence should be addressed to Tao Xia; xiatao62@ahau.edu.cn
}

Received 2 March 2019; Accepted 18 April 2019; Published 29 May 2019

Academic Editor: Yang Xu

Copyright (C) 2019 Qianying Dai et al. This is an open access article distributed under the Creative Commons Attribution License, which permits unrestricted use, distribution, and reproduction in any medium, provided the original work is properly cited.

The effects of the added $\beta$-cyclodextrin $(\beta-\mathrm{CD})$ in the tea infusion extraction on color quality of green tea (Camellia sinensis) infusion have been investigated in detail. Due to the added $\beta-\mathrm{CD}$, the color of the tea infusion can be brightened effectively, and meanwhile, compared to conventional extraction, the retentions of tea polyphenols, catechins, and chlorophyll have also been proved to be increased greatly. Furthermore, the additive $\beta$-CD can also increase the viscosity of the tea infusion. In addition, the existing $\beta$-CD can lower the oxygen solubility ratio in tea infusions effectively, from which a high-quality tea infusion can be prepared ready for further processing.

\section{Introduction}

Tea beverage is one of the most popular and ancient nonalcoholic drinks in the world. Various phytochemicals in the tea, such as flavonoids, tannins, and catechins, are important daily antioxidants for millions of people and may provide additional health benefits. Regular consumption of green tea may contribute to a reduction in cardiovascular disease and some cancers [1-4]. Improving the quality of this important beverage is a long-term objective of the agricultural and food industries. After heat extraction through the addition of boiling water, the first step of making tea beverages, characteristics of the tea infusion, such as color, flavor, and taste, can be deteriorated easily due to the improper operations. For more than a decade, lots of researching efforts have been paid on finding a new, suitable extraction technology that can improve the quality of tea [5-8].

$\beta$-Cyclodextrin $(\beta-\mathrm{CD})$ is used in many countries and considered to be a safe additive [9]. Recently, $\beta$-CD has widely been used during the manufacture of different foods, including green tea beverage [10]. Reports and patents have described how the $\beta$-CD benefits the quality of green tea beverage, such as prevention of milk down [11], prevention of retort odor formation [12], and inhibition of bitterness and astringency [13]. However, these researches mainly focus on the chemical embedding function of $\beta-\mathrm{CD}$, and $\beta-C D$ as the macromolecular compound, will vary the physical properties of the tea infusion systems, such as the color and viscosity, which have never been involved in the past. Here, we have investigated the effects of the additive $\beta$-CD on the quality of tea infusion by examining color stability, viscosity, and dissolved oxygen levels.

\section{Materials and Methods}

2.1. Materials. Fresh tea leaves were harvested and produced at Anhui Agriculture University. The moisture content of the final tea product was $3.29 \%$. The processed tea leaves were sieved (No. 18, $1 \mathrm{~mm}$ ), vacuum packaged in polypropylene (PP) plastic bags, and then stored in a $4^{\circ} \mathrm{C}$ storage room. One day prior to use, bags of tea leaves were removed from the storage room and kept in desiccators at room temperature overnight.

2.2. Chemicals and Reagents. Gallic acid (GA), caffeine $(\mathrm{CAF})$, epicatechin (EC), catechin (C), epigallocatechin gallate (EGCG), epigallocatechin (EGC), and epicatechin gallate (ECG) were obtained commercially from Sigma-Aldrich, USA. Acetonitrile and methanol (chromatographic grade) 
were purchased from Tedia Company, USA. Ethyl acetate, acetic acid, hydrochloric acid (analytical grade) and other standard chemicals were purchased from Shanghai Chemical Reagent Co., Shanghai, China. $\beta$-CD $(\mathrm{C} 42 \mathrm{H} 70 \mathrm{O} 35$, MW 1135.00) was from Fluka Chemicals Co., Switzerland. All solutions were prepared with distilled, deionized water.

2.3. Preparation of Tea Infusion. One gram of the tea sample was extracted in $100 \mathrm{~mL}$ distilled water at $85^{\circ} \mathrm{C}$ for $15 \mathrm{~min}$. The extracted tea infusions were filtered with $0.8 \mu \mathrm{m}$ cellulose filters. Infusions prepared by conventional extraction were control samples. The treated samples were prepared by adding $0.05 \%(\mathrm{w} / \mathrm{v}) \beta-\mathrm{CD}$ to $1 \mathrm{~g}$ of the tea sample in $100 \mathrm{~mL}$ distilled water at $85^{\circ} \mathrm{C}$ for $15 \mathrm{~min}$. Five samples were prepared for each treatment. Both control infusions and $\beta$-CD-treated infusions were stored in glass bottles with lids at $4^{\circ} \mathrm{C}$.

2.4. Measurement of Color. The color of tea infusion was measured by CM-3500d L*a* ${ }^{*}$ spectrophotometer (Konica Minolta Sensing INC.) and calculated as the product of the $\mathrm{L}^{*} \mathrm{a}^{*} \mathrm{~b}^{*}$ system. In this system, " $\mathrm{L}$ " indicates the lightness of tea infusion; the positive values of "a" indicate redness, and the negative values of "a" indicate greenness; and the positive values of " $b$ " indicate yellowness and the negative values of " $b$ " indicate blueness. Decreases in the value of " $L$ " and increases in the value of "a" and "b" indicate the development of brown color. Data and chromatism figure were recorded by this system's accompanying software.

2.5. Analysis of Tea Infusion Main Components. The concentration of each tea infusion was determined as previously described in [14]. Solids extraction yield (SEY) was calculated from the following equation:

$$
\begin{aligned}
\operatorname{SEY}\left(\mathrm{g} \cdot \mathrm{kg}^{-1}\right)= & \text { solids concentration }\left(\mathrm{g} \cdot \mathrm{ml}^{-1}\right) \\
& \times \frac{\text { infusion volume }}{\text { tea dry weight }(\mathrm{kg})} .
\end{aligned}
$$

The main components, such as tea polyphenols (TP), tea polysaccharides (TPS), proteins, chlorophylls (CHL), and pectins, were measured according to Tea biochemistry experimental course [15]. Theanine quantitative analysis was determined with HPLC-PDAD (high-performance liquid chromatography-photo diode array detector) as described in [16]. The catechins and caffeine were quantified by HPLC (Waters 600 Controller, USA) through a C18 column (Phenomenex Synergi 4u Fusion-RP80, $4.6 \times 250 \mathrm{~mm}$ ) and eluted at a flow rate of $1.2 \mathrm{ml} / \mathrm{min}$ by the mobile phase (1\% acetic acid as solvent $\mathrm{A}$, acetonitrile as solvent $\mathrm{B}$ ) at $25^{\circ} \mathrm{C}$. The gradient elution conditions were as follows: from $90 \% \mathrm{~A}: 10 \% \mathrm{~B}$ to $87 \% \mathrm{~A}: 13 \%$ B for the first $20 \mathrm{~min}$ and then to $70 \% \mathrm{~A}: 30 \% \mathrm{~B}$ from 20 to $40 \mathrm{~min}$. The UV absorbance of the eluent was monitored at $280 \mathrm{~nm}$ with Waters 2487 Dual Absorbance Detector running the Millennium 32 software.
2.6. Chlorophyll Fluorescence Intensity within Tea Infusion. Chlorophyll fluorescence intensity within $400 \mu \mathrm{L}$ of tea infusion was measured by FLUOROLOG-3-TAV (Horiba Jobin Yvon, France). Fluorescence spectra of the chlorophylls were recorded at the speed of $150 \mathrm{~nm} / \mathrm{s}$ at $341 \mathrm{~nm}$ excitation wavelength.

2.7. Viscosity Measurements. Viscosity of the tea infusions was made using a coaxial cylinder viscometer NDJ-5 and Ubbelohde viscometer (Shanghai Glass Co., Shanghai, China). All experiments were conducted at ambient temperature $\left(20^{\circ} \mathrm{C}\right)$ using a thermostatic bath (Rheometrics Inc. Shanghai, China).

2.8. Dissolved Oxygen Measurements. After $2 \mathrm{~mL}$ tea infusion was dropped into a special cell and sealed, the dissolved oxygen was measured according to the handbook of Hansatech Oxylab (Hansatech Co. USA) at $20^{\circ} \mathrm{C}$. Zero oxygen signals were proofed and established by the addition of $200 \mu \mathrm{l}$ distilled water saturated with sodium sulfite to the cell.

2.9. Statistical Analysis. Analyses of soluble solid content, color, and turbidity were run in triplicate and averaged. Statistical analysis was carried out using Duncan's multiplerange test. Significance of difference was defined at $P<0.05$.

\section{Results and Discussion}

3.1. Color of Tea Infusion. In order to compare physical characteristics of tea infusions processed with or without $\beta$-CD treatment, the color of infusions was measured using a spectrophotometer over a period of 20 days. Initially, the "L," "a," and "b" values of the tea infusions made via the two extraction methods were not significantly different (Table 1).

Both tea extracts were clear and greenish yellow, due to the high content of chlorophylls in the infusions, as shown in Table 1. However, as storage progressed, tea infusions containing $\beta$-CD demonstrated better color-staying ability. For example, the lightness "L" value remained high, at $72.1 \pm 4.6$ in the $\beta$-CD tea, while it dropped to $60.3 \pm 3.3$ in the conventionally brewed tea after 20 days. This increase in lightness is likely due to the ability of cyclodextrins to form inclusion complexes with many organic substances and enhance solubility in water [17]. Likewise, the greenness values $(-a)$ were similar right after extraction but became dissimilar over time during storage. The "a" value remained low at $4.5 \pm 1.0$ in the $\beta$-CD-containing tea but rose to $14.4 \pm 3.2$ in the untreated tea at the $20^{\text {th }}$ day. As reported, $\beta$-CD forms inclusions with chlorophylls since the $\beta$-CDchlorophyll inclusion stabilizes and improves the solubility of chlorophyll in aqueous solutions [18].

The color of the $\beta$-CD-containing tea infusion remained greener than that of the conventional extraction. Also, the color of the tea infusions made by $\beta$-CD-assisted extraction had lower amounts of red and brown colors (B) during storage (Figure 1). However, since the color of tea infusion is 
TABLE 1: Effects of $\beta$-CD on the color of tea infusion.

\begin{tabular}{lcccc}
\hline \multicolumn{1}{c}{ Extraction methods } & & & Storage time (days) & \\
& & 0 & $89.449 \pm 3.220$ & 20 \\
\hline \multirow{3}{*}{ Conventional extraction } & $\mathrm{L}$ & $95.397 \pm 3.000$ & $-2.552 \pm 0.099$ & $60.275 \pm 3.307$ \\
& $\mathrm{a}$ & $-3.304 \pm 0.231$ & $27.890 \pm 1.736$ & $14.440 \pm 3.211$ \\
& $\mathrm{~b}$ & $17.915 \pm 1.091$ & $90.071 \pm 3.639$ & $69.125 \pm 6.372$ \\
\hline \multirow{3}{*}{ Extraction with $\beta$-CD } & $\mathrm{L}$ & $95.575 \pm 3.788$ & $-3.022 \pm 0.103$ & $72.063 \pm 4.579$ \\
& $\mathrm{a}$ & $-3.666 \pm 0.0973$ & $26.885 \pm 1.311$ & $4.527 \pm 1.100$ \\
& $\mathrm{~b}$ & $17.927 \pm 2.306$ & $53.073 \pm 3.043$ \\
\hline
\end{tabular}

Each value represents mean \pm standard deviation (SD) of ten individual measurements. L: lightness; a: positive values (redness), negative values (greenness); b: positive values (yellowness), negative values (blueness).

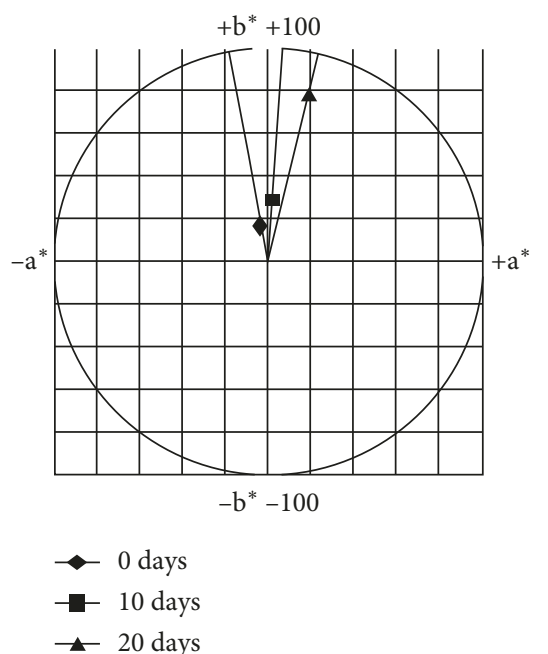

(a)

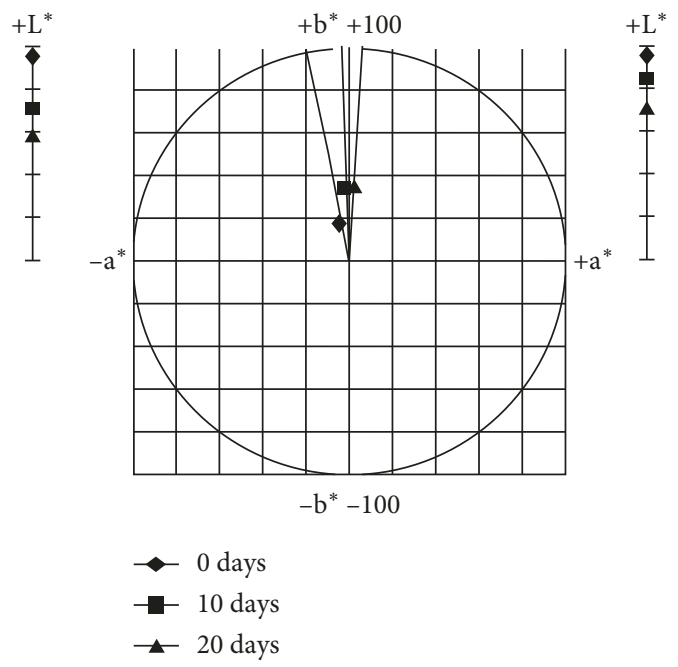

(b)

Figure 1: Chromatism of tea infusion during storage. (a) Conventional extraction. (b) Extraction with $\beta$-CD. Tea infusion extracted with or without $\beta$-CD was stored at $4^{\circ} \mathrm{C}$ for 20 days. The samples were analyzed for lightness $(\mathrm{L})$, redness $(+\mathrm{a})$, greenness $(-\mathrm{a})$, yellowness $(+\mathrm{b})$, and blueness $(-\mathrm{b})$. Measurements were conducted on a total of 5 samples for each treatment.

affected by many factors, such as content and stability of carotenoids, anthocyanins, and flavanols [19], and their interactions, the mechanism through which $\beta$-CD affects the color of green tea requires additional investigation.

\subsection{Effect of $\beta-C D$ on Chemical Composition in Tea Infusion.}

Tea infusion concentration and chemical composition were determined both in control and in $\beta$-CD-treated infusions. In the control samples, made using the conventional extraction method, the SEY was $498.4 \pm 1.0 \mathrm{~g} / \mathrm{kg}$. The additive $\beta$-CD resulted in an SEY of $496.3 \pm 1.1 \mathrm{~g} / \mathrm{kg}$ (Table 2). These results were not significantly different (at $P=0.05$ ) and indicated that the total solid extraction yield was not affected by the additive of $\beta$-CD.

Polyphenols, amino acids, and caffeine are the main components of tea infusions and determine the taste and color of tea beverages. Biochemical analyses showed that the content of tea polyphenols, catechins, and chlorophylls were significantly higher in tea infusions extracted with the addition of $\beta$-CD than in those of conventionally extracted infusions, despite similar total SEYs. For example, total polyphenols increased from $236.6 \pm 12.1$ to $252.5 \pm 17.8 \mathrm{~g} / \mathrm{kg}$ and chlorophylls more than doubled from $0.5 \pm 0.1$ to $1.2 \pm 0.6 \mathrm{~g} / \mathrm{kg}$ (Table 2). These results indicated that $\beta$-CD could selectively enhance the solubility of certain organic compounds, which was similar to previous results $[17,20]$. Also affected was the content of pectin, which was less in tea infusions with $\beta$-CD-assisted extraction than in conventionally extracted infusions $(37.1 \pm 1.9$ vs. $30.5 \pm 2 \mathrm{~g} / \mathrm{kg}$, Table 2). This result indicated that extraction with $\beta$-CD inhibited pectin solubility, which may decrease the formation of tea cream downs. There were no significant changes in other tested compounds between these two infusion procedures.

In several published reports, addition of $\beta$-CD has enhanced chlorophyll's light and heat stability [21]. In order to verify the impact of $\beta$-CD on the chlorophyll content of tea beverage, we measured the intensity of chlorophyll fluorescence in tea infusion at different $\beta$-CD concentrations (Figure 2). At $680 \mathrm{~nm}$, the characteristic emission wavelength of the chlorophyll, fluorescence intensity of chlorophyll, and $\beta$-CD concentration was positively correlated. The intensity of chlorophyll fluorescence in tea infusion was significantly higher with increasing amounts of $\beta$-CD added during the extraction, as compared to control fluorescence 


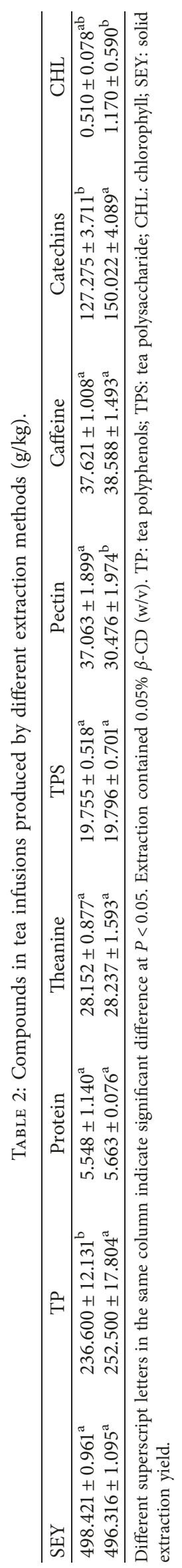




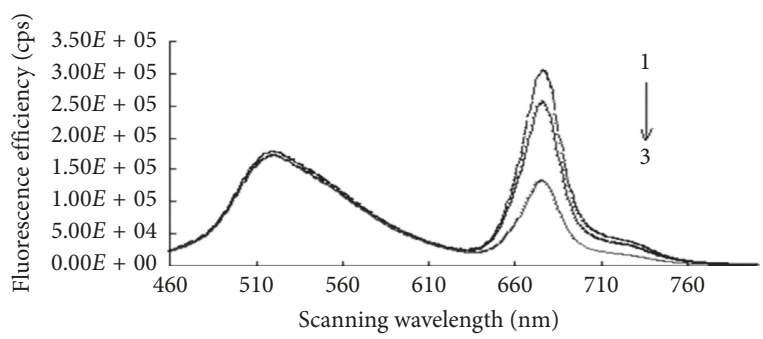

FIGURE 2: Fluorescence spectra of chlorophylls in green tea infusion at different $\beta$-CD concentrations ( $\beta$-CD concentrations: $1: 0.2 \% ; 2$ : $0.05 \%$; 3 : $0 \%$ ) concentration used in above experiments.

intensity in the sample with $0.05 \% \beta$-CD during the extraction is more than double that of the infusion without $\beta$-CD, which indicates that $\beta$-CD has a significant solubilization effect on chlorophyll. At $2 \% \beta-\mathrm{CD}$, the fluorescence intensity further increases.

3.3. Effects of $\beta-C D$ on Viscosity of Tea Infusion. The viscosity of the tea infusion increased with the addition of low concentrations of $\beta-\mathrm{CD}$, increasing by $2 \%$ with the addition of $0.05 \% \beta$-CD (Figure 3 ). However, the maximal viscosity was obtained at this low concentration, which would be remained constant after $0.05 \% \beta$-CD. Changes in viscosity were saturated above $0.1 \% \beta-\mathrm{CD}$, which is in agreement with characteristics of macromolecules in a colloidal solution [17].

According to the theory of colloidal chemistry, at the lower concentrations, particles in the solution interact with $\beta-\mathrm{CD}$, which increases the viscosity of the solution with increasing $\beta$-CD. However, after some point, the interactions-primarily hydrogen bonding-between particles have completely been saturated by $\beta$-CD. At this point, additional $\beta$-CD has no additional effect, and the reaction is past concentration dependence. The electrostatic repulsion between the particles was enhanced by $\beta-C D$, which keeps the infusion stably dispersed.

3.4. Effects of $\beta-C D$ on Dissolved Oxygen in Tea Infusion. We compared the dissolved oxygen content in distilled water samples with different concentrations of $\beta$-CD. Additive $\beta$-CD decreased oxygen diffusion into distilled water (Figure 4). It took water samples longer to reach oxygen saturation when $\beta$-CD was added. For example, the distlled water samples without $\beta$-CD were saturated with oxygen after 1.8 hours, but the distilled water containing $0.05 \%$ $\beta$-CD would reach oxygen saturation after 4.1 hours. The time to reach oxygen saturation will be proportion to the $\beta$-CD concentration when $\beta$-CD concentration is lower than $0.1 \%(\mathrm{w} / \mathrm{v})$. However, when $\beta$-CD concentration is higher than $0.1 \%(\mathrm{w} / \mathrm{v})$, it will take 5 hours to get oxygen saturation (Figure 4). This tendency agreed with the relationship between $\beta$-CD concentration and viscosity (Figure 3 ). Perhaps the increased viscosity increased the surface tension of the distilled water, reducing the rate of diffusion at the airaqueous interface, but not altering the solubility of oxygen in the solutions. This is the first report on the effect of $\beta-C D$ on dissolved oxygen in distilled water.

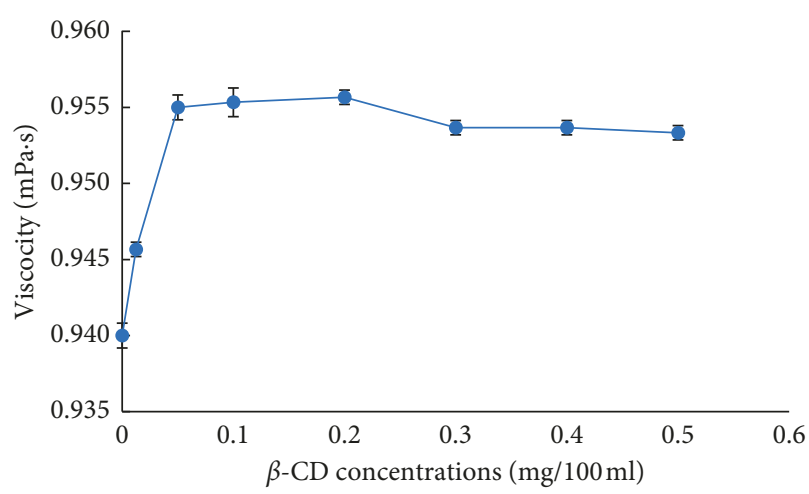

FIGURE 3: Effects of $\beta$-CD concentrations on viscosity of tea infusion.

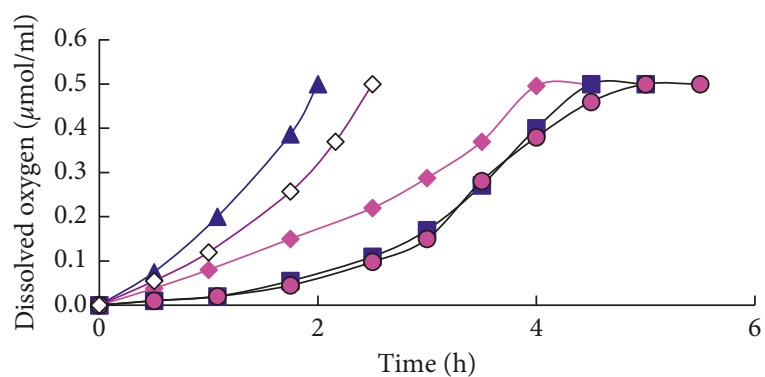

FIGURE 4: Effect of $\beta$-CD concentrations on dissolved oxygen in distilled water. Solid line with " $\mathbf{\Delta}$ " is $0 \% \beta-C D$; solid line with " $\diamond$ " is

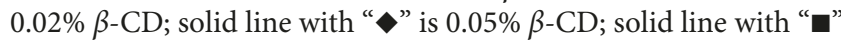
is $0.1 \% \beta$-CD; solid line with "•" is $0.5 \% \beta-C D$.

After understanding how $\beta$-CD affects dissolved oxygen in distilled water, its effects on tea infusion have also been analyzed. The dissolved oxygen in control tea infusion reached its maximum level of $0.333 \mathrm{~mol} / \mathrm{ml}$ within 30 minutes and then decreased sharply, to almost zero, after an hour (Figure 5). The maximum dissolved oxygen in tea infusion extracted with $\beta$-CD was $0.036 \mu \mathrm{mol} / \mathrm{ml}, 10$-fold lower than control. Then, dissolved oxygen levels remained at almost zero during storage. However, the overall levels of oxygen in tea infusion were lower than that in water, suggesting that stored tea consumes oxygen, which would reduce the availability of health effective components in the tea beverage. This study demonstrated that $\beta$-CD blocked oxygen dissolution in tea infusions, which paved the way to promote the quality of stored tea beverage.

There are headspace oxygen, dissolved oxygen, diffuse oxygen, and entrapped oxygen in the bottled liquid [22]. This oxygen, especially dissolved oxygen, can accelerate the enzymatic browning, oil oxidation, ascorbic acid degradation, flavor deterioration, and antioxidant activity of fruits and vegetables [23].

Many efforts have been conducted to remove dissolved oxygen during processing and storage of beverage [24-26]. Deoxidizer and filling nitrogen are widely used to remove oxygen to maintain high quality of tea in the process of processing and storage [27]. However, the effect of dissolved oxygen on tea beverage has not been reported. Our experimental results demonstrated that due to existing $\beta$-CD, 


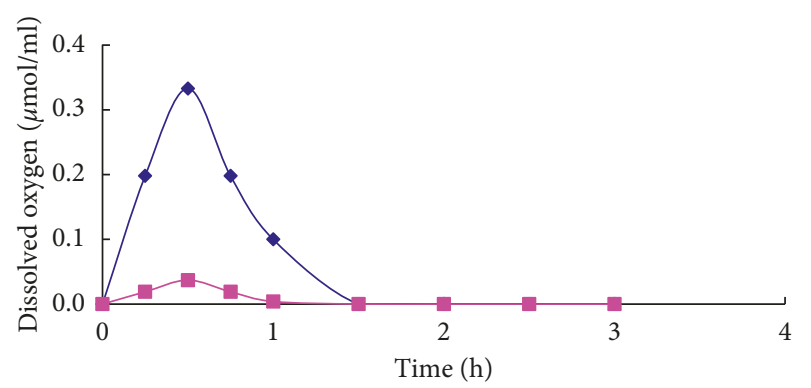

FIGURE 5: Effects of $\beta$-CD on dissolved oxygen in tea infusion. Solid line with “" represents conventional infusion; solid line with " $\square$ " represents infusion made with $0.05 \% \beta$-CD when extraction. Dissolved oxygen levels were measured from aliquots of the same sample or from different samples over the course of 3 hours.

it took longer time to get oxygen saturation in distilled water and the maximum dissolved oxygen is much lower in tea infusion compared to those without $\beta$-CD. As for the mechanism of this phenomenon, what the specific effect on color, aroma, and taste of tea infusion toned to be further investigated in future.

\section{Conclusions}

Boiling water extraction is a key processing step for the tea beverages. This work compares the properties of tea made by conventional extraction and extraction in the presence of $\beta$-CD. Positive effects of $\beta$-CD on the color quality of tea infusion have been demonstrated in experiments. Addition of $0.05 \% \beta$-CD during the extraction will result in more chlorophyll dissolved in the tea infusion, which can increase the greenness of the beverage color. Furthermore, the viscosity of the tea infusion has also been increased by adding just $0.05 \% \beta$-CD. And, for the first time, the effects of $\beta$-CD on dissolved oxygen content in both distilled water and tea infusion have been investigated and demonstrated in experiments, from which we can observe that the additive $\beta$-CD can lower the oxygen solubility ratio in tea infusions effectively. Together, these data indicate that the addition of the compound $\beta-\mathrm{CD}$, which is generally recognized as safe for human consumption, will improve storage qualities of processed tea beverages.

\section{Abbreviations}

$\begin{array}{ll}\beta \text {-CD: } & \beta \text {-Cyclodextrin } \\ \text { HPLC: } & \text { High-performance liquid chromatography } \\ \text { HPLC- } & \text { High-performance liquid chromatography- } \\ \text { PDAD: } & \text { photo diode array detector } \\ \text { TP: } & \text { Tea polyphenols } \\ \text { TPS: } & \text { Tea polysaccharide } \\ \text { CHL: } & \text { Chlorophyll } \\ \text { SEY: } & \text { Solid extraction yield. }\end{array}$

\section{Data Availability}

The data used to support the findings of this study are included within the article.

\section{Conflicts of Interest}

All the authors declare no conflicts of interest.

\section{Authors' Contributions}

Qianying Dai and Tao Xia conceived and designed the study. Qianying Dai and Sitong Liu drafted the manuscript. Yurong Jiang and Huozhu Jin performed the experiments and analyzed data. Qianying Dai and Sitong Liu contributed equally to work.

\section{Acknowledgments}

This work was supported by the National Nature Science Foundation of China (NSFC) (Grant nos. 331772057 and 31101355).

\section{References}

[1] S. K. Connors, G. Chornokur, and N. B. Kumar, "New insights into the mechanisms of green tea catechins in the chemoprevention of prostate cancer," Nutrition and Cancer, vol. 64, no. 1, pp. 4-22, 2012.

[2] F. D. Domenico, C. Foppoli, R. Coccia, and M. Perluigi, "Antioxidants in cervical cancer: chemopreventive and chemotherapeutic effects of polyphenols," Biochimica et Biophysica Acta, vol. 1822, no. 5, pp. 737-747, 2012.

[3] M. Hessien, S. El-Gendy, T. Donia, and M. A. Sikkena, "Growth inhibition of human non-small lung cancer cells H460 By green tea and ginger polyphenols," Anti-Cancer Agents in Medicinal Chemistry, vol. 12, no. 4, pp. 383-390, 2012.

[4] S. Yusuke, M. Jae-Hak, S. Kanzo, and W. Naoharu, "Effects of structure on radical-scavenging abilities and antioxidative activities of tea polyphenols: NMR analytical approach using 1,1-diphenyl-2-picrylhydrazyl radicals," Journal of Agricultural \& Food Chemistry, vol. 53, no. 9, pp. 3598-3604, 2005.

[5] T. Miyashita and H. Etoh, "Improvement of the bitterness and astringency of green tea by sub-critical water extraction," Food Science and Technology Research, vol. 19, no. 3, pp. 471-478, 2013.

[6] A. Perva-Uzunalić, M. Škerget, Ž. Knez, B. Weinreich, F. Otto, and S. Grüner, "Extraction of active ingredients from green tea (Camellia sinensis): extraction efficiency of major catechins and caffeine," Food Chemistry, vol. 96, no. 4, pp. 597605, 2006.

[7] T. Xia, S. Shi, and X. Wan, "Impact of ultrasonic-assisted extraction on the chemical and sensory quality of tea infusion," Journal of Food Engineering, vol. 74, no. 4, pp. 557560, 2006.

[8] Y. Yoshida, M. Kiso, and T. Goto, "Efficiency of the extraction of catechins from green tea," Food Chemistry, vol. 67, no. 4, pp. 429-433, 1999.

[9] G. Astray, C. Gonzalez-Barreiro, J. C. Mejuto, R. Rial-Otero, and J. Simal-Gándara, "A review on the use of cyclodextrins in foods," Food Hydrocolloids, vol. 23, no. 7, pp. 1631-1640, 2009.

[10] W. Bi, S. Li, and K. H. Row, "Eco-friendly separation of catechins using cyclodextrins as mobile phase additives in RPHPLC," Phytochemical Analysis, vol. 23, no. 4, pp. 308-314, 2012.

[11] M. Katsukiko, "Prevention of milk down of tea extracts by cyclodextrin," Seito Gijutsu Kenkyn Kaishi, vol. 4, no. 41, pp. 71-75, 1993. 
[12] K. Hitoshi, "Prevention of retort odor formation in green tea drinks with cyclodextrin," Gekkan Fudo Kemikaru (Japan), vol. 10, no. 10, pp. 137-142, 1994.

[13] H. Mori, M. Nishioka, and F. Nanjo, "Cyclodextrin and cyclofructan for inhibition of bitterness and astringency of foods and beverages," JP Patent 67894, 2006.

[14] Y. Liang and Y. Xu, "Effect of $\mathrm{pH}$ on cream particle formation and solids extraction yield of black tea," Food Chemistry, vol. 74, no. 2, pp. 155-160, 2001.

[15] Z. Zhengzhu, Tea Biochemistry Experimental Course, China Agriculture Press, Beijing, China, 2009.

[16] Q. Shi, L. Chen, Z. Z. Zhang, L. I. Ping, and X. C. Wan, "A method for determination of L-theanine with HPLC-PDAD in tea," Journal of Anhui Agricultural University, vol. 33, no. 3, pp. 347-350, 2006.

[17] J. Pang, X. U. Qiu-Lan, Y. J. Sun, F. S. Zhang, and S. P. Tian, "Studies on rheological properties of konjac-tea drink," Journal of Northeast Agricultural University, vol. 10, no. 2, pp. 173-181, 2003.

[18] P. L. Dentuto, L. Catucci, P. Cosma et al., "Effect of cyclodextrins on the physicochemical properties of chlorophyllain aqueous solution," Journal of Physical Chemistry B, vol. 109, no. 3, pp. 1313-1317, 2005.

[19] S. Yasuyo and S. Yuzo, "Identification of chlorophylls and carotenoids in major teas by high-performance liquid chromatography with photodiode array detection," Journal of Agricultural and Food Chemistry, vol. 51, no. 18, pp. 53075314, 2003.

[20] M. L. Calabrò, S. Tommasini, P. Donato et al., "Effects of $\alpha$ and $\beta$-cyclodextrin complexation on the physico-chemical properties and antioxidant activity of some 3-hydroxyflavones," Journal of Pharmaceutical and Biomedical Analysis, vol. 35, no. 2, pp. 365-377, 2004.

[21] S. Teng and B. H. Chen, "Formation of pyrochlorophylls and their derivatives in spinach leaves during heating," Food Chemistry, vol. 65, no. 3, pp. 367-373, 1999.

[22] D. R. Johnson and E. A. Decker, "The role of oxygen in lipid oxidation reactions: a review," Annual Review of Food Science and Technology, vol. 6, no. 1, pp. 171-190, 2015.

[23] I. V. Bree, B. D. Meulenaer, S. Samapundo et al., "Predicting the headspace oxygen level due to oxygen permeation across multilayer polymer packaging materials: a practical software simulation tool," Innovative Food Science and Emerging Technologies, vol. 11, no. 3, pp. 511-519, 2010.

[24] F. J. Garcíaalonso, S. Bravo, J. Casas, D. Pérezconesa, K. Jacob, and M. J. Periago, "Changes in antioxidant compounds during the shelf life of commercial tomato juices in different packaging materials," Journal of Agricultural and Food Chemistry, vol. 57, no. 15, pp. 6815-6822, 2009.

[25] A. Llorens, E. Lloret, P. A. Picouet, R. Trbojevich, and A. Fernandez, "Metallic-based micro and nanocomposites in food contact materials and active food packaging," Trends in Food Science \& Technology, vol. 24, no. 1, pp. 19-29, 2012.

[26] Y. Byun and S. Whiteside, "Ascorbyl palmitate- $\beta$-cyclodextrin inclusion complex as an oxygen scavenging microparticle," Carbohydrate Polymers, vol. 87, no. 3, pp. 2114-2119, 2012.

[27] Z. Huang and L. Gu, "Research progress of green tea preservation technology," Modern Agricultural Science and Technology, vol. 20, pp. 348-351, 2009. 

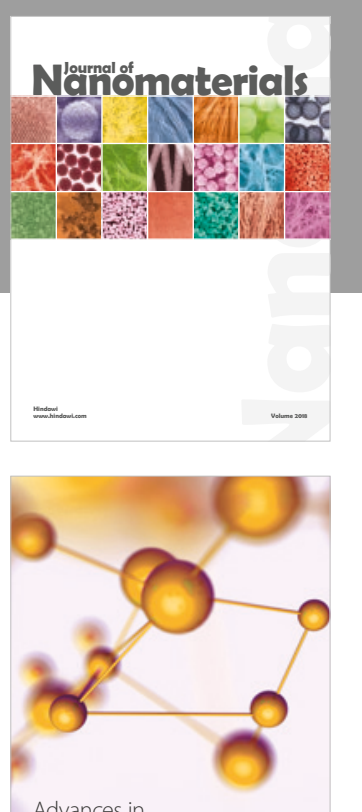

Physical Chemistry
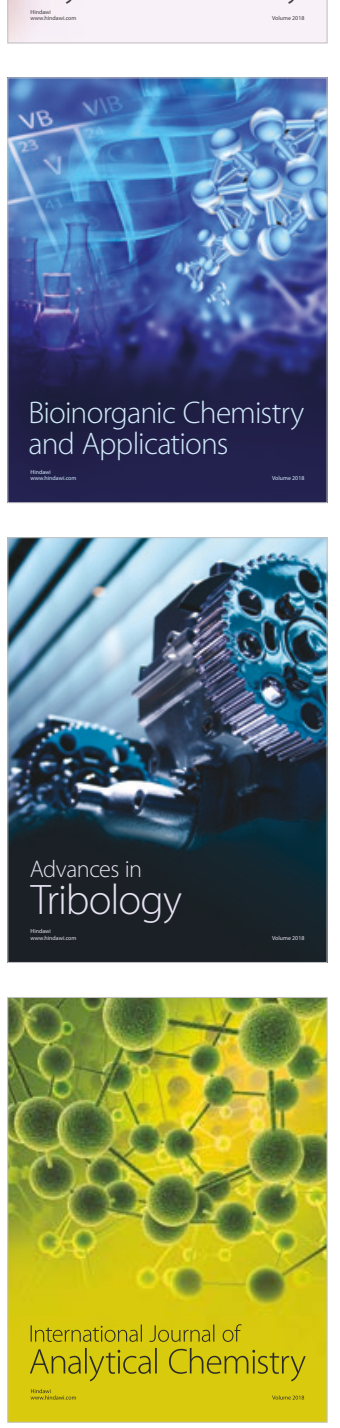

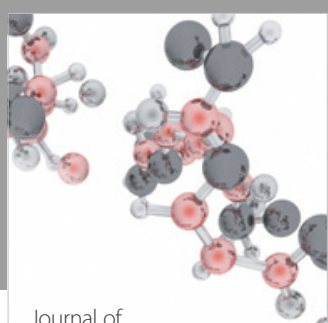

Analytical Methods

in Chemistry

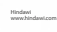

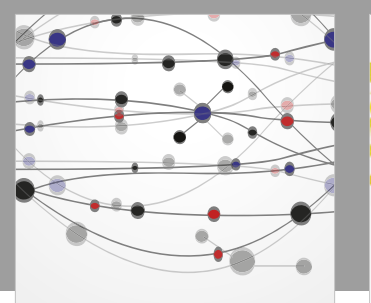

The Scientific World Journal

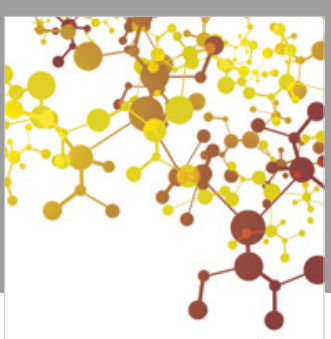

Journal of

Applied Chemistry
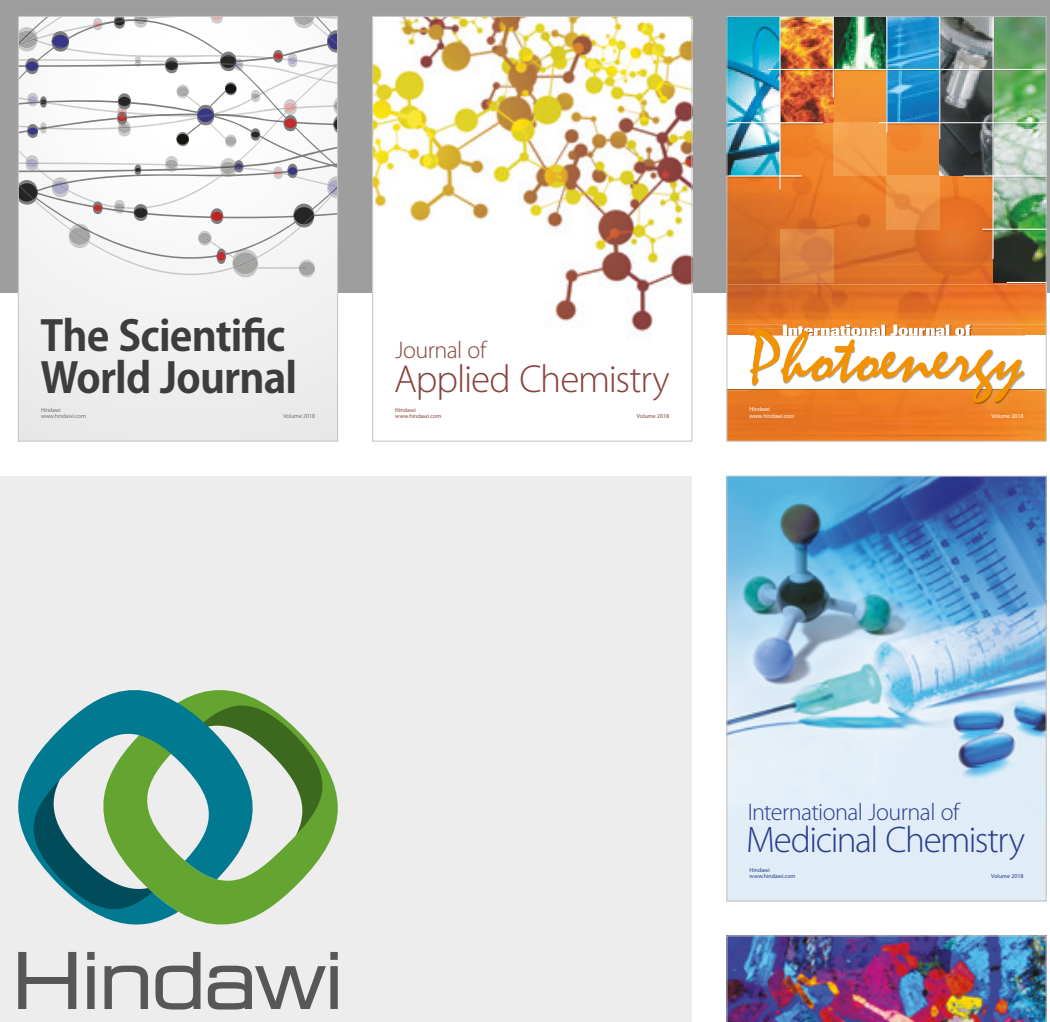

Submit your manuscripts at

www.hindawi.com
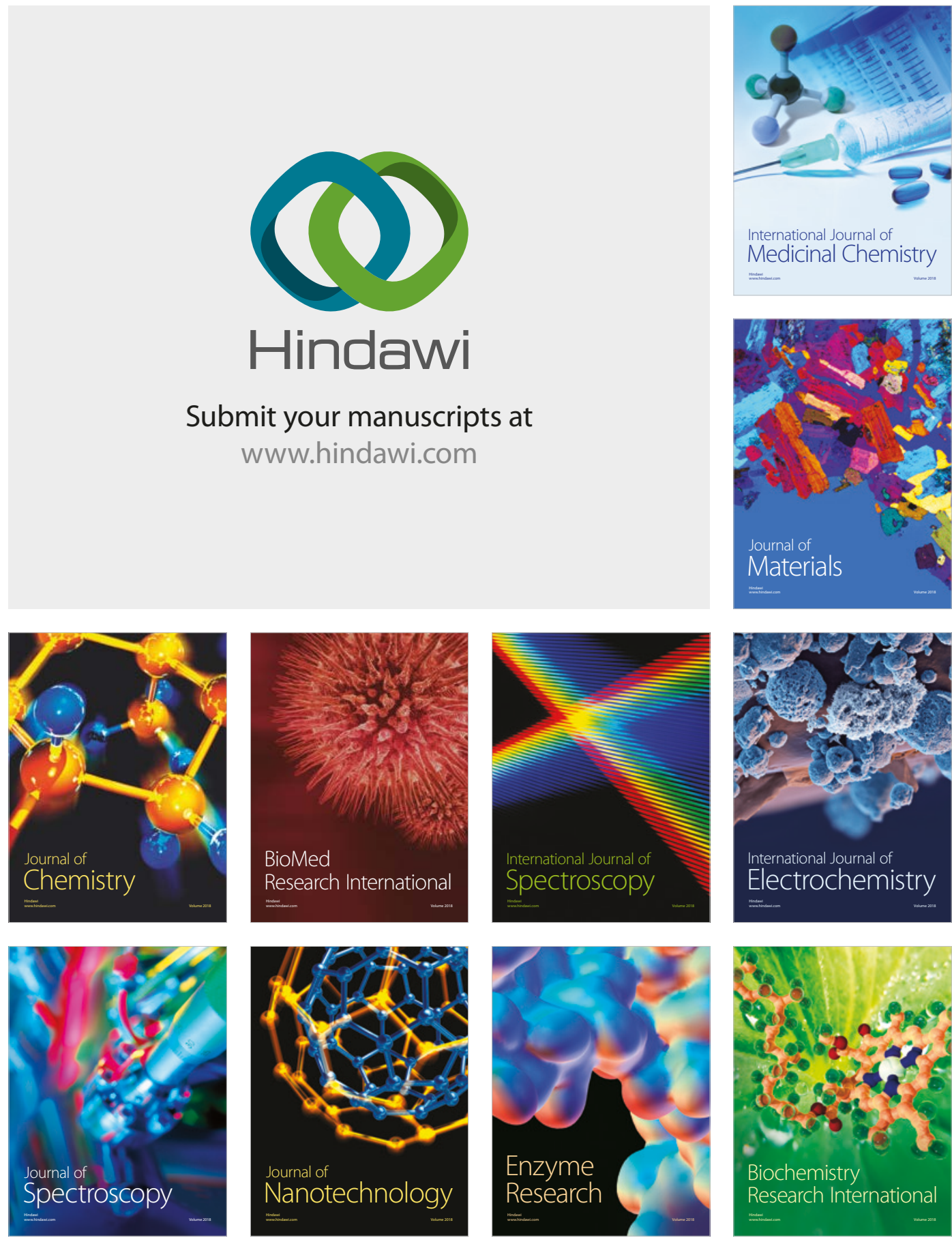
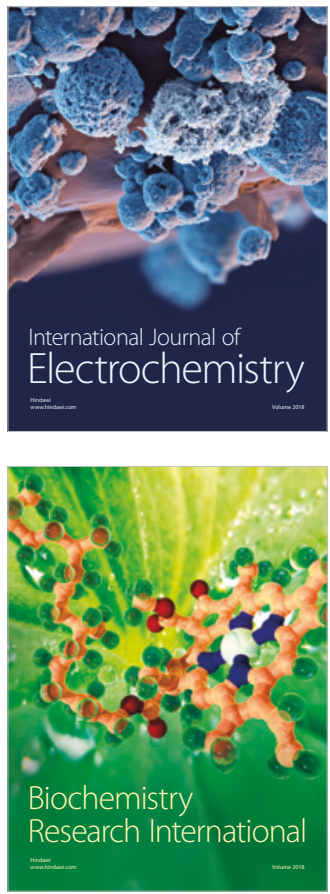